\title{
Evaluation of the Effectiveness of Pedicled Buccal Fat Pad Graft for Repair of Oro-Antral Communications
}

\author{
Natashekara Mallesh ${ }^{1}$, Hussameldien Hussien², M. V. Akshatha ${ }^{3}$ \\ 1Department of Oral and Maxillofacial Surgery, VS Dental College and KIMS Hospital, Bangalore, \\ Karnataka, India. ${ }^{2}$ My Dentist, Manchester, UK. ${ }^{3}$ Department of Orthodontics and Orthopaedics, \\ Coorg Institute of Dental Sciences, Kodagu, Karnataka, India.
}

\section{ABSTRACT}

\section{BACKGROUND}

Oro-antral communication is a complication associated with extraction of maxillary posterior teeth, surgeries of the maxillary sinus or pathologies associated with the sinus or the posterior maxilla. Such abnormal communications need to be repaired at the earliest, to maintain oral and nasal complex harmony and to prevent undue complications thereafter. These communications can be repaired by various methods, one of those being buccal fat pad pedicled graft technique which will be clinically evaluated and critically discussed in this paper. The pre-operative, immediate and post-operative measures followed, the eligibility criteria chosen, and the duration of follow up period, will formulate the outline for the study. A careful assessment of the criteria, clinical signs and healing is noted, to establish the outcome of the technique.

\section{METHODS}

An observational study was undertaken to evaluate the effectiveness of a surgical technique to repair oro-antral communications wherein the pedicled buccal fat pad is used as a graft material. 20 patients with OAC, who were presented to the department of Oral \& Maxillofacial Surgery, VS Dental College \& Hospital, Bangalore, were recruited for the study. The clinical study was conducted in accordance with the protocol and the results were evaluated on the basis of patient's comfort towards the procedure, ease of technique, healing time, post-operative complications and recurrence rate of the communication. Details of the technique and a review of the previous studies published were discussed in detail, to form a relevant summary.

\section{RESULTS}

The clinical study utilised buccal pad of fat as a pedicled graft for the closure of oroantral communication and the study was compared with previous studies published regarding the same. The technique was found to be more effective and convenient than the other methods to both the patient and operator, owing to its ease of performing, minimal risk of complications from the grafted site and the harvest site, and predictable healing.

\section{CONCLUSIONS}

The technique is easiest among the various methods recommended so far, pertaining to the procedure and predictability. Although, the training and experience of a skilled operator is equally important in achieving the best results.

\section{KEY WORDS}

BFP, Buccal Fat Pad Graft, OAC Repair, OAF Closure, Evaluation of Technique, Success, Prognosis
Corresponding Author:

Dr. Natashekara Mallesh,

\#48, Sarathy Apt., Flat No. 001A,

$13^{\text {th }}$ Cross, Malleshwaram,

Bangalore-560003,

Karnataka, India.

E-mail: drnshekhar@yahoo.co.in

DOI: $10.14260 /$ jemds/2020/136

Financial or Other Competing Interests: None.

How to Cite This Article:

Mallesh N, Hussien H, Akshatha MV. Evaluation of the effectiveness of pedicled buccal fat pad graft for repair of oroantral communications. J. Evolution Med. Dent. Sci. 2020;9(09):613-618, DOI: 10.14260/jemds/2020/136

Submission 13-11-2019,

Peer Review 03-02-2020,

Acceptance 11-02-2020,

Published 02-03-2020. 


\section{BACKGROUND}

Oro-antral communication is a pathological communication between the oral cavity and maxillary sinus, occurring due to trauma or as a complication of surgeries in posterior maxilla, as a result of pathologies, as a complication following the extraction of maxillary premolars and molars. ${ }^{(1,2)}$ Also, rarely it may be the result of pathological entities like noma, syphilitic gumma, leprosy, leishmaniasis and secondary to sequalae of radiation therapy, removal of tumour or cyst of the palate or antrum, gunshot injuries and even as an iatrogenic injury associated with minor oral surgical procedures. Usually, an oro-antral communication defect less than $2 \mathrm{~mm}$ in width will close spontaneously, when the communication is more than $4 \mathrm{~mm}$, it needs immediate intervention to close the communication appropriately before 48 hours of occurrence. Failure to do so will result in oroantral fistula and other complications of oral, nasal and maxillary sinus cavities such as maxillary sinusitis. Over the years, various surgical techniques have been proposed for the repair of oro-antral communications such as flap advancement techniques, bone grafting with or without barrier membrane, third molar as a barrier of oro-antral communication and other techniques. $(1,2,3)$ However, these techniques have not always provided fully satisfactory results. The common complications are the reduction of vestibular depth in buccal sliding flap, painful secondary healing and scaring of donor site in the palatal rotational flap and secondary infection and recurrence in bone graft techniques. Oro-antral communications are common enough oral surgical problems to warrant a continual research for an improved technique for its repair.

In the recent years, the utilisation of buccal fat pad as a pedicled graft was proposed by Zoran Stajcic. (4) and Yasuo Hanazawa et al., (5) They found the technique is simple and an effective alternative for the routine methods. In 1977, Egyedi first published the use of buccal fat pad as a pedicled graft for the closure of oro-antral and oro-nasal communications wherein he used a split thickness skin graft to line the oral side of the exposed fat graft. Since then, there have been two significant developments. The first was reported in 1983, when Neder A described the use of buccal fat pad as a free graft for intra-oral defects. This was followed by Tideman $\mathrm{H}$ in 1986, who showed that the pedicled fat pad graft when unlined, would epithelialise in about 1 to 4 weeks and therefore, the use of split thickness skin graft was not necessary. (6) In this present clinical study, the unlined buccal pad of fat as pedicled graft was used for the closure of oroantral communications to evaluate the effectiveness of the technique and dealt with in-detail.

The aim of this clinical study is to evaluate the effectiveness of buccal fat pad pedicled graft technique for closure of Oro-antral communications. The purpose of choosing this method is easy availability of the graft near to the recipient site, ease of technique for the surgeon, reliable technique and predictable outcome of the treatment. The effectiveness of the procedure and its predictability, in comparison to other methods is dealt in detail below.

\section{METHODS}

The effectiveness of the surgical technique of buccal pad of fat as a pedicled graft for closure of Oro-antral communication is taken as the topic of consideration of this clinical evaluation study. 20 patients were selected for the clinical study. The sample size was limited to 20 , depending on the number of patients who reported with set eligibility criteria within the stipulated time and to better understand the clinical effectiveness of the surgical procedure. The patients were those who presented to the department of Oral \& Maxillofacial surgery, VS Dental College and Hospital, Bangalore, Karnataka. The observational study design was formulated and proposed with ethical committee of the institution for the approval to conduct the study. After careful reviewing of the study design and set criteria, the approval was granted. An informal consent form was signed by all the patients willing to participate in the study in advance. The oro antral communication in the selected patients was treated with pedicled buccal fat pad graft and the healing and effectiveness of the procedure was evaluated. The results were evaluated on the set parameters which includes patient's tolerance to the procedure, ease of the surgical technique, duration of healing, post-operative complications like herniation of graft, infection, graft necrosis, excessive granulation and residual communication.

\section{Inclusion Criteria}

Patients with the following set criteria were selected for the study.

- Patients aged below 55 years.

- $\quad$ No history of systemic disease, head and neck surgeries.

- No history of radiation therapy.

- Oro-antral communication of at least $4 \mathrm{~mm}$ in diameter and recent/ fresh report of communication (not exceeding time lapse of 48 hours between the occurrence of communication and reporting to the hospital for direct closure alone.

- $\quad$ Patient should be available for periodic follow-up.

\section{Surgical Site Anatomy}

Buccal Pad of Fat (BFP): It is a disc-like tissue composed of fat, comprising a main body with 4 extensions namely buccal, pterygoid, and superficial temporal and deep temporal, and surrounded by microvasculature supplied by maxillary artery, facial and superficial temporal arteries. It lies beneath the buccal mucosa, extending up to the zygomatic arch, on either side. It is a glandular like, intermuscular tissue separating the muscles of mastication from each other and from their originating bone. It is made of a specialized fat termed' Syssarcosis' and consists of lobules that are yellowish white in colour. A thorough understanding of the anatomy of the graft site helps in minimising the complications and predict the prognosis of the procedure.

\section{Parts of BFP and Its Relations}

The BFP has central body and four extensions. The buccal process is the most superficial and the pterygoid extension lies medial of the mandibular ramus. Deep temporal process is fixed to the BFP body, and the superficial temporal extension is separated from the body by the deep temporal 
fascia. In general, the buccal extension of the buccal fat pad is the largest segment, accounting for about 30 to 40 percent of the total weight and by volume. The body is slightly smaller, representing 25 to 35 percent of the total weight. The sizes of the pterygoid and deep temporal extensions are inconsistent but are usually smaller than either body or buccal extensions. The parotid duct, zygomatic and buccal branches of the facial nerve are intimately associated with the buccal fat pad. They cross the lateral surface of the fat pad as they enter the cheek.

\section{Surgical Technique}

Prior to the surgery, the patients were advised routine blood investigations such as Haemoglobin, TC, DC, ESR, BT, CT, PT, PTT and INR. Radiological investigations such as the Intra Oral Periapical view, Orthopantomogram (OPG) and Water's view radiographs and general physical examination and vital parameters BP and TPR are recorded.

Patients were diagnosed with Oro-antral Communication (OAC) with the help of presenting signs and symptoms such as bleeding from the nostril, escape of air through the socket during expiration, frothing or bubbling of blood in the socket, escape of fluids from the mouth through the nostril. In addition to these, fistulas were also presenting with halitosis, nasal discharge, salty taste and dull pain in the maxillary region. Clinical examination of the reported cases with the help of visual assessment, water holding test and radiographical evaluations were made to confirm the diagnosis of OAC. Once the Oro-antral communication is diagnosed, the method of surgical closure is decided. If the patients satisfy the eligibility criteria, buccal fat pad pedicled graft method of closure is performed. Prior to treatment, the patients were started on a prophylactic antibiotic course comprising of Amoxicillin $1000 \mathrm{mg}$ - one hour before the procedure.

The surgery was performed under local anaesthesia using lignocaine $2 \%$ with adrenaline in 1 in 80,000 concentrations or general anaesthesia with endotracheal intubation depending upon the clinical demand. The site of surgery was scrubbed with betadine. The margins around the Oro-antral communication along with the epithelialized fistula was first excised with a no. 15 blade. Two divergent vertical releasing incisions from the crest of the alveolar bone up to the vestibule were placed on either side of the communication. The sinus was approached through canine fossa, to clear sinus pathologies, if any. To access the buccal pad of fat, a second horizontal incision measuring about $0.5 \mathrm{~cm}$ long is placed in the periosteum over the reflected mucoperiosteal flap posterior to the zygomatic buttress. BFP is loosely attached to the submucosal layer, giving it an added advantage in release and advancing. The buccal pad of fat is then accessed through that periosteal incision by gently introducing a curved haemostat in posterior-superior-lateral direction and opening the beaks of the haemostat inside to create submucosal tunnel. This manoeuvre is repeated, if necessary, until the BFP appeared into the tunnel created. Care is taken not to injure the underlying vasculature. The buccal fat pad generally gets herniated to the tunnel created and then it will be eased across the desired site with as little tension as possible to the graft tissue. Once the buccal fat pad sufficiently obturates the OAC passage, it is gently sutured to the palatal mucoperiosteal tissue or gingiva. Buccally raised mucoperiosteal flap is then repositioned back to its original place and vertical releasing incisions are sutured to secure the flap in position. Resorbable (Vicryl 4-0) suture was used to secure the flap and graft. The buccal fat pad graft was kept unlined to achieve secondary intention healing by gradual epithelisation. No barrier membrane or surgical dressing was used.

Following the procedure, the patients were instructed (i) not to chew on the side of the surgery performed, (ii) to apply cold compression extra orally over the area of procedure for 48 hours post-op, (iii) to be on soft diet for at least 14 days, (iv) to avoid vigorous gargling, (v) to avoid blowing the nose, and to hold the mouth wide open during cough and sneeze (horse Sneezing), (vi) to avoid smoking, (vii) to avoid straws for drinking liquids, (viii) to avoid playing any wind blowing instruments and (vi) to take medications as prescribed: Tab. Amoxicillin $500 \mathrm{mg}$ - thrice daily for 5 days, Tab. Metronidazole $400 \mathrm{mg}$ - thrice daily for 5 days, Tab. Paracetamol and Ibuprofen combination- thrice daily for 5-7 days. Mouthwash Chlorhexidine $0.2 \%$ - thrice a day to be used as a gentle rinse. Patients were advised to report for periodic follow up at 24, 48 and 72 hours after the procedure. Later they were reviewed at the interval of one week for 4-6 weeks. Common complications associated with this procedure are extra oral oedema, bleeding through the nose, secondary infection at the surgical site, scarring of the buccal mucosa and transient obliteration of the buccal vestibule.

\section{RESULTS}

The clinical study conducted on patients to evaluate the effectiveness of buccal pad of fat as a pedicled graft for the closure of Oro-antral communication, has been evaluated based on the outcome and complications if any associated with the procedure. Total 20 patients of OAC were treated using unlined pedicled BFP graft in the present study. Among the 20 patients, 14 were male and 6 were female, contributed the sex distribution of $70 \%$ males and $30 \%$ females. Age of the patients ranged from 14 to 55 years. OACs most frequently appeared in patients in $3^{\text {rd }}$ and $4^{\text {th }}$ decades in our study.

It was observed that the surgical procedure and healing was uneventful in all the patients. Minor complications such as extra-oral swelling pertaining to the site of surgery as a post-operative sequalae, traumatic ulcers at the site of surgery and dull pain were observed. However, the complications were found to be manageable and resulted in no morbidity in all the patients. The technique was performed diligently with expertise under asepsis and sterilization protocol. Hence, no sign of secondary infection was observed. Primary healing was satisfactory in all the patients and the time taken for complete healing varied among the patients. Duration ranged from 2 to 4 weeks for complete healing and the 4-0 Vicryl sutures gradually resorbed and left-over sutures were retrieved. Following the soft tissue healing, clinically performed tests such as water holding test, nose blowing test and radiographs were repeated to evaluate the success of closure of the Oro-antral communication and for any persistent residual communication. 
In three of the patients, BFP applied to OAC was slightly in excess. It was surgically contoured in the second week once it sufficiently granulated. Hence in these patients the healing was completed by fourth post-operative week. In rest of the patients, the healing was completed by third post-operative week. Partial superficial necrosis of BFP was noticed in 2 patients but, did not seem to have any influence on the final result. No significant reduction in the depth of buccal sulcus was observed in any of the operated patients. Additionally, sensory recovery in the BFP grafted site was recovered about 3-4 weeks post-operatively. In our study, we found that the repair of oro-antral communication using pedicled buccal fat pad graft is a simple technique and resulted in almost $100 \%$ success.

\begin{tabular}{|c|c|c|c|c|c|c|}
\hline $\begin{array}{l}\text { Sl. } \\
\text { No. }\end{array}$ & $\begin{array}{l}\text { Post-0p. } \\
\text { Condition }\end{array}$ & \begin{tabular}{|c|} 
Total \\
Cases \\
$(\mathrm{N})$ \\
\end{tabular} & $\begin{array}{c}\text { Present } \\
\text { Frequency } \\
\text { (Percentage) }\end{array}$ & \begin{tabular}{|c|} 
Absent \\
Frequency \\
(Percentage)
\end{tabular} & $\begin{array}{c}\mathbf{f} \\
\text { Value }\end{array}$ & $\begin{array}{c}\text { p- } \\
\text { Value }\end{array}$ \\
\hline 1 & Partial necrosis & \multirow{3}{*}{20} & $01(5 \%)$ & $19(95 \%)$ & \multirow{3}{*}{2.976} & \multirow{3}{*}{$0.059^{*}$} \\
\hline 2 & $\begin{array}{c}\text { Excessive } \\
\text { granulation }\end{array}$ & & $04(20 \%)$ & $04(80 \%)$ & & \\
\hline 3 & $\begin{array}{c}\text { Herniation of fat } \\
\text { pad }\end{array}$ & & $00(0 \%)$ & $20(100 \%)$ & & \\
\hline
\end{tabular}

Table 1. Comparison of the Conditions After Treatment with Pedicled Buccal Fat Pad Graft using One Way ANOVA Test

${ }^{*}$ Indicates statistically significant difference between the groups

\begin{tabular}{|c|c|c|c|c|c|}
\hline $\begin{array}{l}\text { Sl. } \\
\text { No. }\end{array}$ & Cause of OAC & $\begin{array}{c}\text { Total } \\
\text { Cases }(\mathrm{N})\end{array}$ & $\begin{array}{c}\text { Frequency } \\
\text { (Percentage) }\end{array}$ & t Value & p Value \\
\hline 1 & Cyst Enucleation & \multirow{2}{*}{20} & $4(20 \%)$ & \multirow{2}{*}{4.62} & \multirow{2}{*}{$1.000(\mathrm{NS})$} \\
\hline 2 & Extraction & & $16(80 \%)$ & & \\
\hline & Compari & $\begin{array}{l}\text { betwee } \\
\text { Using }\end{array}$ & $\begin{array}{l}\text { s of Oro-A } \\
\text { ed t-Test }\end{array}$ & & \\
\hline
\end{tabular}

\section{DISCUSSION}

Oro-antral communication is either a fresh perforation or an established fistula. A perforation is a fresh communication, the time elapsed since its occurrence not exceeding $48 \mathrm{hrs}$. When the interval before the communication comes under treatment exceeds $48 \mathrm{hrs}$, it is considered as a fistula. The Oro-antral fistula (OAF), on the other hand, is an epithelialized tract extending into the sinus cavity. This may be acute or chronic oro-antral fistula, wherein the fistula if present for less than 14 days, is termed 'acute', and if exceeded, they are termed 'chronic oro-antral fistula'. They commonly occur following extraction of maxillary posterior teeth and sometimes due to oral or nasal cavity pathologies. They often present with symptoms such as regurgitation of fluids through the nose, salt like taste at the site and throat, mild dull pain, escape of air through the communication and inability to drink using the straw. Once diagnosed, they are treated to repair oro-antral communication. For defects less than $3 \mathrm{~mm}$, generally no intervention is necessary, and they are likely to heal spontaneously. $(7,8)$

Scott. P. et al., published a report in 2004, utilising the buccal pad of fat for the closure of oro-antral communication. It was observed that even when the buccal fat pad is alone utilised for the closure of oro-antral communication after excision of the sinus tract, the healing was uneventful, favourable and the graft was stable (9). The study reported the success of $100 \%$ in the 50 cases on which the procedure was performed. However, the article did not include the size of oro-antral communication and whether it influenced the outcome of the procedure.

W.L. Adeyemo. et al., performed a literature review and reported a study of closing the oro-antral communication with pedicled buccal fat pad. The study report detailed the procedure performed for a chronic oro-antral fistula present for around 5 years and that has been performed oro-antral repairs previously without any success. The repair of the fistula by pedicled buccal fat pad yielded success with the initiation of epithelialisation and soft tissue healing within 4 weeks. (7) The report has detailed the history of fistula, providing for the feasibility of this technique even in chronic oro-antral communications. However, one study report may not be considered sufficient scientific data, for the indication.

Nezafati S. et al., conducted a comparative study to evaluate the clinical outcome of pedicled buccal fat pad versus buccal sliding flap procedure. It was observed that pain and swelling were more evident in the pedicled group than the buccal flap group. (10) Maximum mouth opening reduction was more in buccal sliding flap group. However, no notable differences were observed in the healing of the surgical site. The study has taken the pain, swelling and maximum mouth opening as parameters of evaluation of the success of the surgical procedure. Although minor differences favouring the buccal sliding group were observed, evaluation of subjective parameters may not be totally reliable for the consideration.

Batra H. et al., performed a literature review to evaluate the effectiveness of various modalities for the closure of Oroantral communication. The study considered buccal advancement flap, buccal fat pad and a combination of these 2 techniques. (1) For Oro-antral repair of lesser dimension farther from the $3^{\text {rd }}$ molar region, buccal advancement flap is preferred and for fistulas and communications close to the posterior regions of the maxilla, buccal fat pad is preferred. No indication or advantage was observed for the combination technique. Zoran Stajcic. et al., published an article report in 1992 on the utilisation of unlined buccal fat pad in 56 extraction cases and found the technique to be $100 \%$ successful with no obliteration of buccal sulcus. ${ }^{4}$

Yasuo Hanazawa. et al., conducted a similar study on 14 patients, the outcome of which was found to be successful in 13 patients. (5) The initiation of epithelialization was found to occur in 3 weeks and the success rate was found to be high. Another study conducted by Khandelwal. P. that compared the different surgical techniques available for closure and repair of Oro-antral communications. It was observed that for small defects in the premolar region, buccal sliding flap technique is performed. For Oro-antral communications that have developed recently, the palatal flap is preferred and for fistulas and recurrent communication, buccal fat pad technique is preferred. (2) The study is a clinical evaluation report that adjudged all the techniques routinely performed for oro-antral repair and has formulated the above conclusion. The results are for individual procedures and not for a combination of techniques. Bravo CG. et al., performed a literature review on Bichat's fat pad role in the closure of the Oro-antral fistula. Bichat's fat pad is the buccal pad of fat that is pedicled to close the oro-antral communication and was used in 1977 for the first time. (11) It offers numerous advantages such as predictable healing, lesser chances of complications and lesser morbidity associated with the 
procedure. Afshin H. composed a report article on the use of buccal fat pad for oro-antral communication closure. It was concluded that buccal fat pad method was reliable, easy to perform, safe and the epithelialization was initiated within a week of performing the procedure. (8) The report recorded no significant complications associated with the procedure adding to the credibility of the procedure.

Jain MK. et al., conducted a clinical study to evaluate the effectiveness of buccal fat pad in oro-antral repair. The procedure was conducted either alone or in combination with buccal advancement flap where the defects were largely requiring closure in layers. It was observed that no complications were observed in the buccal fat pad technique and the technique when performed alone was sufficient, reliable and effective. (12) The clinical study was conducted in a sample of 15 people which is small to conclude on the results obtained. However, the study has paved a way for larger studies to be conducted in this regard. Krishna Kumar, et al., conducted a study to systematically review the various interventions available for treating oro-antral communications and fistulae due to dental procedures. The study evaluated the pedicled buccal fat pad and buccal flap advancement technique. It was observed that no significant differences were evident one month after the surgery. (3) The study considered one-month post-surgery evaluation as the criteria which are not reliable because of the confounding factor. Also, the studies provided in the review were found to be of poor quality.

Narjiss A. et al., performed a case report and literature review of the surgical closure of oro-antral fistula using buccal fat pad graft. It was observed that soft tissue healing was complete within 2 weeks of surgery and at 1 year follow up, no evidence of surgery is noted. (13) The procedure was observed to be least risky and post-operative phase was uneventful in the case reported in the study. In our present study, among the 20 patients, 2 patients presented with displaced maxillary root pieces which was retrieved by means of Caldwell Luc operation. Also, 1 patient presented with purulent exudate following extraction of maxillary $1^{\text {st }}$ molar with oro-antral communication and 1 patient presented with infected radicular cyst. In both cases, the infected tissue and lining were curetted via Caldwell Luc procedure, a medicated ribbon gauze was packed keeping the one end of the gauge in the nostril performing intranasal antrostomy for easy retrieval later. And then the communication was closed with Buccal fat pad procedure.

Among the 20 patients treated, 19 patients exhibited uneventful healing and soft tissue healing completion in 3 weeks. Only 1 patient presented with recurrent perforation of the Oro-antrum. This was due to the presence of persistent large maxillary sinus pathology, which was removed, and closure was performed with palatal rotational advancement flap in the second attempt. Even though the BFP pedicled graft is a most predictable option, the technique could not be used in this case as BFP graft was already used in the first instance. In our opinion, BFP pedicled graft can be reserved as a rescue technique when other conventional techniques fail. From the data gathered so far from the study as well as the literature, it is evident that the buccal pad of fat pedicled graft is the easy, effective, reliable and preferred technique for closure of oro-antral communication and defects of all sizes $(7,10,8,12,13) .5$ of the studies reviewed have favoured the buccal fat pad pedicled graft for the least complications associated with them. However, one study by Nezafati S. et al., (10) observed complications such as pain and swelling associated with the surgical procedure under discussion but patients did not significantly bother on these 2 complications. Also, the initiation of epithelialisation was found to be earlier in the buccal fat pad technique than the other procedures. $(10,1,8,12)$

When the procedure was performed in combination with buccal advancement technique, no significant benefits were observed. $(2,12,3)$ However, the combination technique is performed in large defects to close the oro-antral fistula in layers wherein the primary reconstruction acts as a scaffold for the healing to occur. The procedure was found to be $100 \%$ successful as observed in a study of sample size 50 (1). Whether the success rate was the same for all the Oro-antral communications, irrespective of the size, duration and aetiology need to be studied. In our present clinical study, the technique is evaluated on a sample size of 20 patients. The healing was uneventful, and epithelialization was complete in 3 weeks with no evident sign of obliteration of vestibule noted at the end of the 1 year follow up. The procedure was found to be simple, safe, easy, effective and predictable. It did not require any dressings and was associated with a smaller number of complications. The procedure is indicated when all other techniques have failed, when the buccal or palatal mucoperiosteum is damaged or when the site needs to be prepared to receive a prosthesis. However, care should be taken to prevent such obliteration in all the patients. No sign of scarring of the tissue was observed.

\section{CONCLUSIONS}

The data from our clinical evaluation study and the literatures compiled have resulted in the following conclusions. The buccal pad pedicled graft technique for closure of oro-antral communications poses the least risk and least complications associated with the procedure. They limit the morbidity. The extent of surgical donor and harvest site is restricted. The flap poses adequate elasticity and vascularity yet is not jeopardised when mobilised to the farther site of repair. The surgical procedure is easy, reliable, accessible and effective for OAC repairs. Even in cases of recurrent or chronic fistula or in cases where the buccal or palatal mucoperiosteum is damaged, the procedure can guarantee successful outcome and good prognosis as suggested by authors Stajcic and Yasuo Hanazawa. In agreement with Stajcic and Yasuo Hanazawa et al., success rate of the procedure is the highest (almost 100\%) amongst all the interventions for the closure of oro-antral communications. Although the procedure is performed with good reliability and predictability, the outcome also depends on the patient's care of the surgical site, in following the post-surgical instructions and reporting for the periodic follow-up.

Closure or repair of oro-antral communication by means of the buccal pad of fat as a pedicled graft, offers numerous advantages to the surgeon as well as the patient, by limiting the morbidity to one side of the oral cavity and also by providing an adequate scaffold for the repair of the communication. The technique is easiest among the various methods recommended so far, pertaining to the procedure 
and predictability, although, the training and experience of a skilled operator is equally important in achieving the best results.

\section{REFERENCES}

[1] Batra H, Jindal G, Kaur S. Evaluation of different treatment modalities for the closure of oro-antral communications and the formulation of a rational approach. Journal of Maxillofacial and Oral Surgery 2010;9 (1):13-8.

[2] Khandelwal P, Hajira N. Management of oro-antral communication and fistula: various surgical options. World Journal of Plastic Surgery 2017;6 (1):3-8.

[3] Krishanappa SKK, Eachempati P, Nagraj SK, et al. Interventions for treating oro-antral communications and fistulae due to dental procedures. Art. No.: CD011784. Cochrane Database of Systematic Reviews 2018;8.

[4] Stajcic Z. The buccal fat pad in the closure of oro-antral communications: a study of 56 cases. Journal of CranioMaxillofacial Surgery 1992;20 (5):193-7.

[5] Hanazawa Y, Itoh K, Mabashi T, et al. Closure of oroantral communications using a pedicled buccal fat pad graft. J Oral Maxillofac Surg 1995;53 (7):771-6.

[6] Tideman H, Bosanquet A, Scott J. Use of the buccal fat pad as a pedicled graft. J of Oral Maxillofac Surg 1986;44 (6):435-40.
[7] Adeyemo WL, Ogunlewe MO, Ladeinde AL, et al. Closure of oro-antral fistula with a pedicled buccal fat pad. A case report and review of the literature. African Journal of Oral Health 2004;1 (1):42-6.

[8] Haraji A, Zare REZA. The use of buccal fat pad for Oroantral communication closure. J Mashhad Dent Sch Mashhad Univ Med Sci 2007;31:9-11.

[9] Scott P, Fabbroni G, Mitchell DA. The buccal fat pad in the closure of oro-antral communications: an illustrated guide. Dental Update 2004;31 (6):363-4, 366.

[10] Nezafati S, Vafaii A, Ghojazadeh M. Comparison of pedicled buccal fat pad flap with buccal flap for closure of oro-antral communication. International Journal of Oral and Maxillofacial Surgery 2012;41 (5):624-8.

[11] Cordero GB, Ferrer SM, Fernández L. Odontogenic sinusitis, oro-antral fistula and surgical repair by Bichat's fat pad: Literature review. Acta Otorrinolaringologica Esp (English Edition) 2016;67 (2):107-13.

[12] Jain MK, Ramesh C, Sankar K, et al. Pedicled buccal fat pad in the management of oro-antral fistula: a clinical study of 15 cases. International Journal of Oral And Maxillofacial Surgery 2012;41 (8):1025-9.

[13] Akerzoul N, Chbicheb S, El Wady W. Surgical closure of oro-antral fistula (OAF) using buccal fat pad graft: a Case Report and Review of Literature. Int J Oral Health Med Res

$2015 ; 2$

(1):32-5. 